\title{
Nem anônimas nem invisíveis: cidade e mulheres escritoras de graffiti
}

Neither anonymous nor invisible: city and women graffiti writers

\author{
Natalia Pérez Torres ${ }^{*}$ \\ *Universidade Federal de Santa Catarina - Florianópolis, SC, Brasil \\ Doutoranda Interdisciplinar em Ciências Humanas (bolsista Capes) \\ nataliaperez.cs@gmail.com \\ https://orcid.org/0000-0003-2608-6589
}




\title{
Resumo
}

Escrever, assumido genericamente no mundo do graffiti enquanto taggear, ou seja, enquanto gesto de intervenção de um suporte não estabelecido para aquilo, o muro, "o espaço tópico da escritura moderna" (Barthes, 2002), supõe uma operação contínua de expressão no espaço público, "um espaço sensível como um todo" (Didi-Huberman, 2017) que surge de um desejo, certo princípio de liberdade, subversão e reivindicação de soberania partilhado entre as/os writers. A voz e a presença das mulheres, uma categoria pensada desde uma "perspectiva ex-cêntrica" (Costa, 2002), não só é cada vez mais visível na prática do graffiti, mas supõe a existência de outra forma de escrita a partir de seus corpos e vivências, configurando outros protocolos de leitura nas cidades. Nesse sentido, propõe-se refletir sobre a autoria de graffiti realizado por mulheres, o processo de escrita e legibilidade da paisagem urbana e as visibilidades e invisibilidades em jogo na apropriação da cidade contemporânea a partir dessa prática artística.

Palavras-chave: cidade; espaço público; mulheres escritoras de graffiti; visibilidade-invisibilidade.

\begin{abstract}
Writing, assumed generically in the world of graffiti as a tagging, that is, as a gesture of intervention of an unexpected support for that, the wall, "the topic space of modern writing" (Barthes, 2002), presupposes a continuous operation of expression in the public space, "a sensitive space as a whole" (Didi-Huberman, 2017) that arises from a desire, a certain principle of freedom, subversion and claim of sovereignty shared between writers. The voice and presence of women, a category thought from an "ex-centric perspective" (Costa, 2002), is not only more visible in the practice of graffiti nowadays, but supposes the existence of another form of writing from its bodies and experiences, setting up other reading protocols in the cities. In this sense, it is proposed to reflect on the authorship of graffiti produced by women, the process of writing and readability of the urban landscape and the visibilities and invisibilities at stake in the appropriation of the contemporary city from this artistic practice.
\end{abstract}

Keywords: city; public space; women graffiti writers; visibility-invisibility. 


\title{
Cidade: entre visibilidades e invisibilidades ${ }^{1}$
}

\begin{abstract}
As cidades, como os sonhos, são construídas por desejos e medos, ainda que o fio condutor de seu discurso seja secreto, que as suas regras sejam absurdas, as suas perspectivas enganosas, e que todas as coisas escondam uma outra coisa [...] As cidades também acreditam ser obra da mente ou do acaso, mas nem um nem o outro bastam para sustentar as suas muralhas. De uma cidade, não aproveitamos as suas sete ou setenta e sete maravilhas, mas a resposta que dá às nossas perguntas.
\end{abstract}

Italo Calvino (1990, p. 44)

Em As cidades invisíveis, Italo Calvino (1990) propõe um protocolo diferenciado de leitura das cidades a partir um intenso trabalho de reflexão no qual o geográfico, o histórico e o simbólico se tecem na narrativa para mostrar os múltiplos sentidos e significados das cidades, as distintas tramas nas que se configura e se realiza a experiência humana nelas. $\mathrm{O}$ apelo à invisibilidade, relativo ao duplo recurso da imaginação e da experiência do autor, que brinca e mistura cidades existentes com cidades sonhadas e do desejo (conjugando passado, presente e futuro, temporalidades e espacialidades, história e memória), remete, desse modo, para o significado mais estendido sobre as cidades no âmbito da antropologia, isto é, que elas são feitas principalmente de relações e de trocas, do não evidente, precisamente daquilo que desafia sua construção física e entra em conflito permanente com o planejamento urbano, criando, como em Isaura, "uma paisagem invisível [que] condiciona a paisagem visível" (Calvino, 1990, p. 24).

As ideias de polifonia e de palimpsesto, mas também as noções de repetição, diferença, imagem de cidade, fragmentação, familiaridade e estranhamento, reconstrução (e destruição), apropriação e fluxos, dentre outras presentes no texto de Calvino, e caras à antropologia urbana (Canevacci, 2004; Gravano, 1999), assinalam de que maneira as cidades fogem da interpretação dicotômica

1 Uma primeira versão deste artigo foi apresentada no II Simpósio do GEFLIT (Grupo de Estudos Feministas na Literatura e na Tradução) realizado na Universidade Federal de Santa Catarina, Florianópolis, em 29 e 30 de outubro de 2018. 
ou de exclusiva referência às "medidas de seu espaço" (Calvino, 1990, p. 14) e respondem, por isso, a uma diversidade de leituras, camadas e sentidos ancorados em temporalidades e espacialidades que se cruzam. Assim, Zaíra será apresentada para nós como efeito das relações entre sua espacialidade e os acontecimentos do seu passado, da mesma maneira em que resultará "inútil determinar se Zenóbia deve ser classificada entre as cidades felizes ou infelizes", pois

não faz sentido dividir as cidades nessas duas categorias, mas em outras duas: aquelas que continuam ao longo dos anos e das mutações a dar forma aos desejos e aquelas em que os desejos conseguem cancelar a cidade ou são por esta cancelados. (Calvino, 1990, p. 36).

Batizadas com nomes de mulher, todas elas variantes de Veneza, as cidades invisíveis de Calvino apontam assim para a questão do desejo pela cidade pelo menos em dois sentidos. Em primeiro lugar, e de acordo com Lilliana Ramos (2012), em termos de um espaço ao qual se conferem, a partir da tradição medieval da cidade desejada, atributos femininos que, "como se falasse do corpo da mulher amada", ${ }^{2}$ devem ser conquistados, tidos "como se a conquista fosse parte da guerra entre os sexos, um passo além das artes da sedução". Aqui não somente se pode evidenciar a ideia da cidade como organismo vivo, ${ }^{3}$ mas também se adverte uma noção de um corpo sustentando uma cidade que se constrói desde o olhar do Outro, e que se constitui, por isso, em objeto de desejo. Um segundo elemento, a partir da leitura das descrições fantásticas que conformam o livro, permite depararmos com a ideia da cidade como espaço inesgotável de expressão e de realização dos desejos dos sujeitos, mas também como lugar de silenciamentos, apagamento e contenção: em suma, um campo sempre em disputa que tem no espaço público o epicentro dos embates entre as distintas formas de vivenciá-la e imaginá-la.

2 As citações extraídas das obras de referência, publicadas em espanhol ou inglês, são de minha livre tradução.

3 Com distintas reformulações o conceito de "organismo vivo" tem se usado desde a publicação em 1961 de A cidade na história de Lewis Mumford (1998) para se referir à configuração multifacetada das cidades, ocupando um lugar permanente dentro da reflexão acadêmica sociológica e urbanística. Hoje, o conceito é trabalhado amplamente ao redor da noção de sustentabilidade e desde uma perspectiva ecológica, principalmente. 
Pensando na especificidade da América Latina, é desde essa última perspectiva que gostaria de colocar a questão da presença de mulheres escritoras de graffiti na cidade contemporânea. Construção coletiva, objeto de desejo e âmbito múltiplo de expressão, sustento que, enquanto gesto, é possível assumir a cidade e a escrita de graffiti realizada por mulheres na tensão entre visibilidades e invisibilidades e seus desdobramentos. No caso das cidades latino-americanas, essa tensão se refere também à sua hibridez, ao fato de condensar nelas fragmentos copiados de muitas outras cidades, atravessadas, em definitivo, "pelo impulso de traduzir de diversas fontes" (Sarlo, 2015, p. 93), o que faz com que a cidade seja feita para ser lida e escrita desde diferentes perspectivas de mundo. Em se tratando das práticas artísticas assumidas por mulheres no espaço público, argumento que existe um duplo regime de invisibilidade na escrita de graffiti de autoria de mulheres que tem a ver tanto com a invisibilidade ainda instalada e validada pelo sistema da arte sobre o trabalho artístico desenvolvido por mulheres quanto com a própria invisibilidade na qual o graffiti se gera na cidade. Nesse sentido, o corpo das mulheres, sua presença no espaço de intervenção, estabelece uma possibilidade de ruptura com a invisibilidade gerida desde as práticas estéticas, ou, em qualquer caso, questiona o modo como as mulheres, nas suas especificidades, se apropriam do espaço público fazendo apelo a estratégias de autoria que transitam entre o anonimato e a invisibilidade.

\section{A cidade é para ser lida e escrita}

Uma das mais instigantes e férteis mostras contemporâneas da reivindicação do espaço público na cidade, entendido como "espaço sensível em sua totalidade" (Didi-Huberman, 2017, p. 157) e, por isso, como lugar de efetivação do desejo, encontra-se na prática do graffiti, um fenômeno artístico e político cada vez mais reconhecido que se inscreve num campo de visibilidade não destinado para ele, o muro, suporte privilegiado de inúmeras expressões urbanas hoje. Dito fenômeno supõe a existência de uma linguagem transgressora, muitas vezes ilegível, que decorre do invisível urbano, uma linguagem que Ricardo Campos (2010, p. 82) define como "uma expressão deslocada, fora do lugar na cidade regulada e disciplinada". 


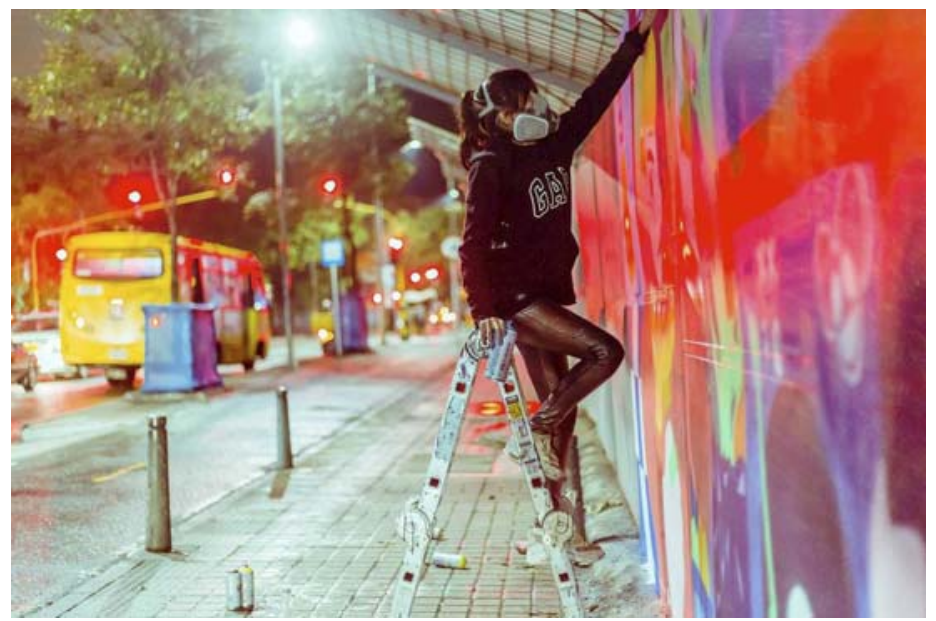

Figura 1. Mugre Diamante (2017) (foto: Camila Castillo).

A presença de graffiti nas cidades implica, paralelamente, reconhecer a existência de domínios diferenciados de linguagem e enunciação, ou seja, de práticas expressivas que se apropriam de algumas características da escrita formal para se distanciar dela, para desafiar e contestar sua imposição (Rama, 1998). No graffiti, entendido neste texto na sua acepção primária de assinar distintos suportes com um pseudônimo ou apelido (o que no vocabulário desse fenômeno urbano se reconhece como fazer uma tag, aproximando esse uso às origens do movimento hip-hop estadunidense da década de 1970), tem lugar uma forma de escrita que dá origem a uma língua política, o que, de acordo com Claudia Kozak (2004, p. 97), "permite a leitura assombrada diante do habitual adormecimento dos sentidos urbanos".

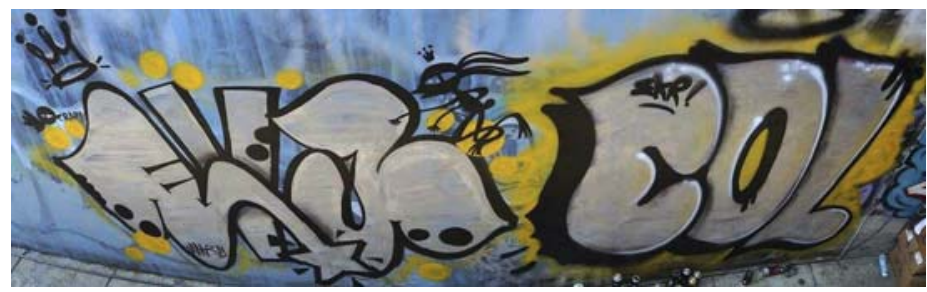

Figura 2. Eva Bracamontes (2015). 
Se, como apontado na introdução deste artigo, a construção do visível-emergente da cidade a partir do invisível-gestual se dá em cumplicidade com o olhar do Outro, na tag se apresenta, com muita força, a tensão entre a vontade de ser visível, o desejo de se exibir, e a regra, que funciona quase como um código de conduta entre as/os writers, as/os escritoras/es de graffiti, ${ }^{4}$ sobre a necessidade de anonimato. Para Lelia Gándara (2015, p. 60) a metáfora do mascaramento, levantada em estudos anteriores sobre esse fenômeno urbano por Armando Silva (1988) e Joan Garí (1995) funciona para assinalar de que forma nas tags, mas também em outros tipos de graffiti (throw up e wild style, por exemplo), combina-se o movimento de mostrar e ocultar, isto é, o desenvolvimento de certa astúcia nas formas de construção da identidade das/os praticantes de graffiti tramadas entre o público e o privado, entre o legal e o ilegal. Esse gesto, no qual anonimato, ilegibilidade e visibilidade se confundem e se misturam, é compreendido desde uma leitura ainda muito amplificada do urbano e do estético que reduz essa ação primária de resistência a uma forma do grotesco ou a um ato de barbárie ou vandalismo: seja como for, a um signo incompreensível e ilegal na paisagem urbana, esfera de comunicação multifacetada e plurívoca, que é preciso combater: ${ }^{5}$

À diferença da simples assinatura, [a tag] supõe um trabalho sobre a forma que normalmente parte de grafemas alfabéticos e os deforma até construir um desenho em que dificilmente reconhecemos unidades de escrita. Quer dizer, que costuma resultar ilegível pela complexidade de sua elaboração formal. Convertido em logograma (um signo que remete a um elemento da linguagem, neste caso um nome) ou num ideograma identificativo, a maioria das vezes somente será interpretável para aquele que conheça seu significado por pertencer ao grupo. Para os outros eventuais leitores será só uma marca esquisita que é reiterada em diversos pontos do espaço urbano. (Gándara, 2015, p. 61).

4 A assunção da prática do graffiti enquanto prática discursiva é, por vezes, mais atribuível às diferentes disciplinas desde as quais ela é estudada do que às/aos próprias/os writers, embora usem essa palavra para definir seu afazer sem distinção da técnica, material ou suporte usado para intervir na cidade. No glossário levantado por Ricardo Campos (2010, p. 299), por exemplo, o writer é tido como "alguém que pinta a aerossol [...] sendo reconhecido como membro de uma comunidade que faz graf-fiti", aproximando a prática, com isso, mais à arte do que a um contradiscurso em e sobre a cidade.

5 Com diferentes propósitos e mecanismos em São Paulo, Buenos Aires e Bogotá tem se executado uma política sistemática de higienização, que, vinculada a um suposto combate à delinquência e à insegurança, vem atacando e censurando, entre outras, as expressões artísticas produzidas na rua. Cf. Gómez Daza e Ester (2017). 
Precisamente, as questões do gesto e do desejo são colocadas por Georges Didi-Huberman como condição de possibilidade dos levantes, tema de sua última curadoria para a exposição itinerante que teve o mesmo nome ${ }^{6}$ e na qual se ocupou das imagens das insurreições contemporâneas. Fundamentado no conceito freudiano de impulso de liberdade (Freiheitsdrang), Didi-Huberman entende ali o desejo como "gesto sem fim", pulsão de vida e de liberdade, um acometimento em que as palavras exclamadas completam o gesto insurreto, por minúsculo que seja, constituindo uma ação de soberania em face da opressão, daquilo que submete os sujeitos e condiciona e cancela seus desejos, e que no âmbito das cidades corresponde a um dispositivo de regulamentações e proibições operantes sobretudo na sua paisagem. O suporte no qual as tags aparecem, configurando outras formas de exclamação da palavra pela via da visibilização da escrita, então, será mais do que relevante para compreender a encenação dos desejos no espaço público, suas distintas formas, agentes e formatos.
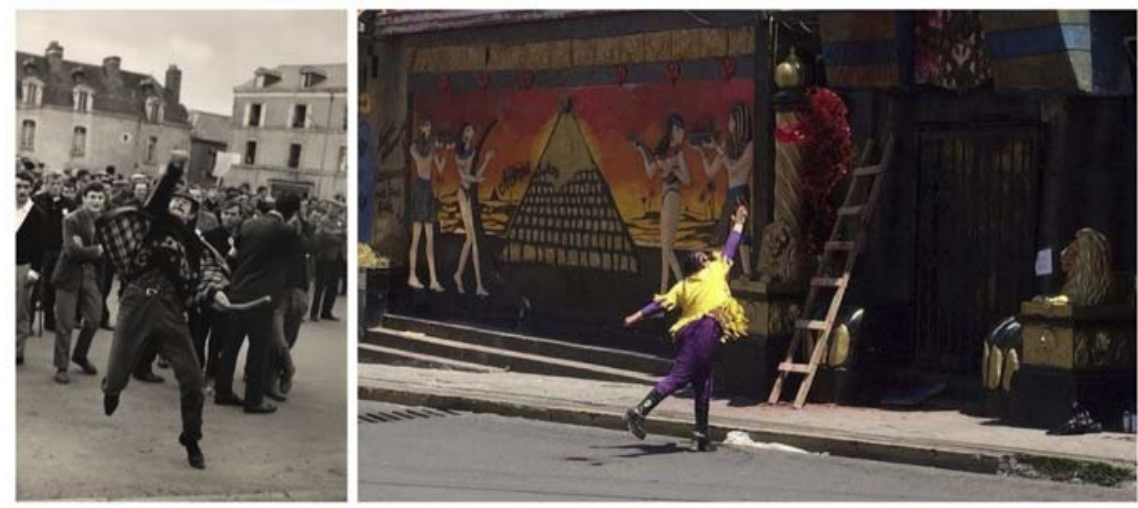

Figura 3. À esquerda: Manifestation paysanne à Redon (1967), Gilles Caron (Simon, 2016); à direita: Mujeres Creando, ação na casa noturna Katanas, La Paz (Mujeres..., 2016).

6 Preparada inicialmente pelo Museu de Arte Contemporânea Jeu de Paume, em Paris, a exposição Levantes, exibida em São Paulo até janeiro de 2018, foi apresentada também em Barcelona e Buenos Aires, Cidade do México e Montreal. Com a particularidade de tratar dos levantes do ponto de vista das emoções coletivas, a proposta concebeu a inserção de obras pertencentes ao registro dos lugares onde se apresentou no intuito de aprofundar a discussão sobre o significado diferenciado das revoltas contemporâneas. Dividida em blocos temáticos, a proposta de Didi-Huberman agrupou os levantes assim: 1) por elementos (desencadeados); 2) por gestos (intensos); 3) por palavras (exclamadas); 4) por conflitos (abrasados); e 6) por desejos (indestrutíveis). 
Na contemporaneidade, a articulação entre muro e graffiti, entre arquitetura e street art, sua inseparabilidade como modalidade de comunicação desde o íntimo para o público (cujos antecedentes podem ser rastreados muito antes da aparição das $\operatorname{tags}^{7}$ pensadas aqui), é constitutiva da configuração dessa forma de escrita que aparentemente não diz nada, mas que constrói seus próprios códigos na cidade. Nesse sentido, já em Variações sobre a escrita Roland Barthes havia afirmado que é o muro que reclama a existência do graffiti para si, configurando o espaço sine qua non da escrita moderna:

Como se sabe, o muro chama à escrita: na cidade não existe uma parede sem graffiti. De alguma maneira, o suporte mesmo possui uma energia de escrita, é ele que escreve e essa escrita olha para mim: não tem nada mais indiscreto do que um muro escrito, porque nada é mais olhado nem lido com uma intensidade maior [...] Ninguém escreve no muro, mas todo mundo o lê. Por isso, emblematicamente, o muro é o espaço tópico da escrita moderna. (Barthes, 2002, p. 131, grifo do autor).

Se o suporte "possui uma energia de escrita", a repetição pode se assumir como o motor dessa expressão incessante no graffiti. Fazer uma tag, essa forma de

7 No trabalho de rastrear os antecedentes históricos do que hoje conhecemos como graffiti, Claudia Kozak consegue identificar, para além das referências à pintura rupestre e aos acontecimentos de Maio de 68 como peças-chave dentro de uma possível genealogia do fenômeno, uma interessante perspectiva sobre a natureza das inscrições encontradas em ruas e banheiros do começo do século XX na Argentina. Em 1904, José María Ramos Mejía publicou o livro Los simuladores del talento en las luchas por la personalidad y la vida, texto no qual se pode evidenciar o protótipo de uma preocupação que não cessou sobre o caráter de uma forma de escrita que aparece para todos, mas que nem todos têm capacidade de decifrar: "Não tem observado nas paredes mil signos extravagantes, mas algumas vezes obedecendo a um plano metódico? Frases e palavras com encadeamentos previdentes, que sugerem a ideia de uma ortografia demoníaca; vocábulos misturados aos variegados transbordamentos plumitivos dos pícaros, cujas aventuras ilustradas por carvões que gesticulam escrevem nas paredes? Com um pouco de trabalho e curiosidade, vocês vão descobrir o misterioso personagem coletivo que ali fala, e à sua maneira, como se não quisesse que outros olhos mais do que os seus penetrassem as emoções, por ele só sentidas [...] Linguagem enérgica, às vezes, com frases quebradas ou interrompidas abruptamente, que passa o sentimento do absurdo, mas cuja tradução tem de ser procurada no quarteirão seguinte para sentir a lógica continuidade de uma frase completa; linguagem sugestiva, livre e de um gosto agreste e caricato, bizarro, isso sim, quando é o agitado fronteiriço, o que com sua mão tremendo confia aos brancos rebocos e à sedutora limpeza das portas, os segredos de suas aflições alucinatórias [...]" (Ramos Mejía, 1904 apud Kozak, 2004, p. 33, grifo do autor). 
"economia expressiva" (Gándara, 2015, p. 36) é a manifestação de um desejo que ultrapassa a territorialização: funciona como princípio de liberdade e soberania compartilhado entre as/os writers. Na figura das/os writers contemporâneos se amalgama, por isso, um uso ousado da arquitetura e da escrita: da primeira como suporte e "página em branco" e o que Leandro de Martinelli (2017, p. 38) chama de "ilusão subversiva", e da segunda como desafio às formas cultas da linguagem:

O graffiti propõe uma ilusão subversiva, o desprezo repetitivo de uma ordem estabelecida que age sobre de outra ilusão: a do continuo urbano. Essa intrusão colorida intervém um espaço que, para muitos, é uma página em branco: as paredes da cidade.

De caráter nômade, clandestino e urbano, dita práxis evidencia que a cidade também é um espaço escrivível nos termos do que Barthes (1992) propôs em $S / Z$, quer dizer, um espaço em que o gesto da mão escrevendo, que evoca a escrita à mão livre, configura "um presente perpétuo", um texto ilegível mas repetitivo que se define, por isso, mais como produção do que como produto, como "a escrita sem o estilo", o que sublinha a polifonia característica das cidades contemporâneas e as disputas pela apropriação do espaço público. Se entendermos por isso que a cidade é para ser lida e escrita, sua legibilidade está dada em função, inclusive daquilo que nos custa decodificar:

O texto escrivível é um presente perpétuo, no qual não se vem inscrever alguma palavra consequente (que fatalmente, o transformaria em passado); o texto escrivivel é a mão escrevendo, antes que o jogo infinito do mundo (o mundo como jogo) seja cruzado, cortado, interrompido, plastificado por um sistema singular (Ideologia, Gênero, Crítica) que venha impedir, na pluralidade dos acessos, a abertura de redes, o infinito das linguagens. O escrivivel é o romanesco sem o romance, a poesia sem o poema, o ensaio sem a dissertação, a escrita sem o estilo, a produção sem o produto, a estruturação sem a estrutura. (Barthes, 1992, p. 34).

Hiato entre escrita e leitura (Gándara, 2015, p. 52), a questão da ilegibilidade pode se assumir como constitutiva da prática do graffiti. Consequentemente, é 
possível comparar o trabalho das/os writers ao de algumas/ns artistas e escritoras/es, primeiro do ponto de vista daquele "desprezo repetitivo de uma ordem estabelecida", e em seguida perante a consideração da escrita como instituição consagrada cujo fim exclusivo é o de comunicar. Esse é o caso da artista argentina Mirtha Dermisache (1940-2012), que desenvolveu, dentro do que se conhece como escrita assêmica, um tipo de "escritas ilegíveis", conceito dado pelo próprio Barthes numa troca epistolar com a artista em 1971, constituindo um repertorio de grafismos, escritas para não serem lidas, que, segundo Belén Gache (2017, p. 30), "evidenciam a vontade de não dizer" e, ao tempo, "focam na dimensão política da escrita, rebelam-se diante dos significados dados", pois "cada rabisco sem sentido, cada símbolo assêmico se constitui numa pausa no uso pretensamente 'normal' da linguagem" e "produz uma parada no decorrer dos sentidos institucionalizados que reproduzimos várias vezes sem nenhuma distância crítica".

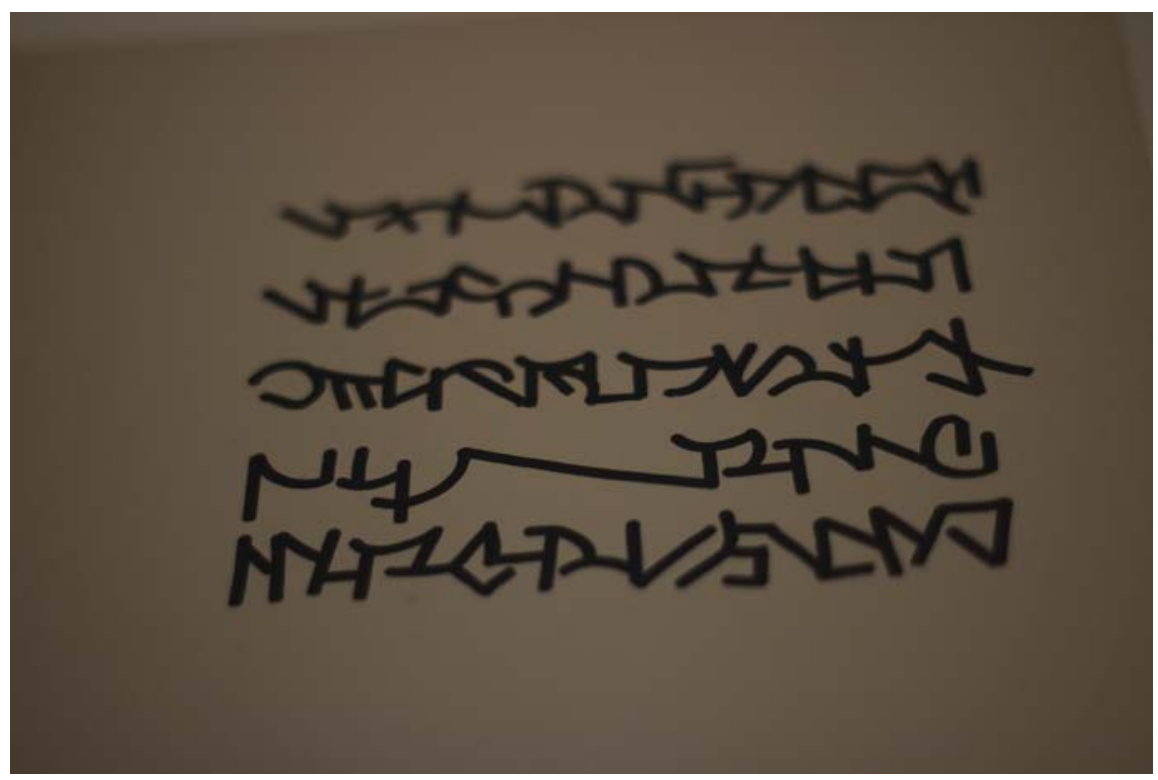

Figura 4. Da série Textos (1971), Mirtha Dermisache (Exposição Mirtha Dermisache Porque iyo escribo!, Museo de Arte Latinoamericano de Buenos Aires - MALBA, Buenos Aires, 11 de agosto a 9 de outubro de 2017 (foto: Natalia Pérez Torres). 
Comparativamente, se a escrita incompreensível e ilegível das/os writers pode se inscrever aquém do seu teor na configuração da paisagem urbana é porque na aparente falta de significados dos traços e das letras, nesse tipo de “desconstrução da escrita" (Gándara, 2015, p. 35), não somente há um desafio aberto a toda institucionalidade e aos cânones - e à autoridade que regula o espaço público e define a partir disso seus usos e contrausos -, mas também a questão do procedimento, do gesto, se revela como fundamento de um tipo de escrita que desafia o poder.

No procedimento e não tanto no produto, então, estaria a condição de legibilidade das tags, uma espécie de escrita na qual não se coloca nada além do nome, mas que partindo disso e sem se preocupar com qualquer intenção literária, definiria o oposto, o diferente, o despreocupado num sentido de desapego institucional, de qualquer tipo de significado diáfano e reconhecível para quem as lê, inseridas dentro de uma linguagem que se assume homogênea. Essa indefinição do sentido da prática e de sua ambiguidade intrínseca, contudo, não resolve o fato de sua incompreensão generalizada, um aspecto que, entre as/os escritoras/ es de graffiti define seu espírito e reafirma seu caráter: no graffiti, a compreensão não depende da escrita, senão que se efetiva nas suas possíveis leituras.

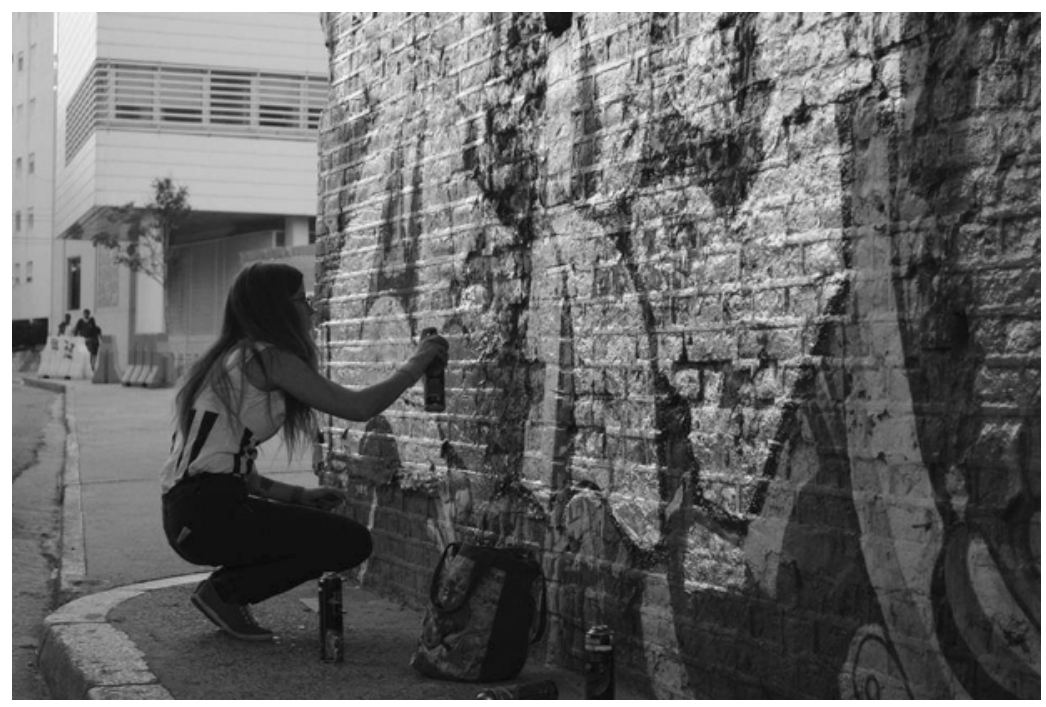

Figura 5. Mickey (2014). 


\section{Mulheres escritoras de graffiti: corpo, invisibilidade e autoria}

A voz e a presença das mulheres, uma categoria pensada a partir de Claudia de Lima Costa (2002, p. 67) desde uma "perspectiva ex-cêntrica", ou seja, "menos pura, menos unificada e a qual percebe a identidade como um lugar de posições múltiplas e variáveis dentro de campo social", não só é cada vez mais visível na prática do graffiti, atingindo maior ressonância e destaque no espaço público, mas supõe a existência de outra forma de escrita desde seus corpos e experiências, configurando outros contextos de leitura e formas possíveis de cultura escrita que partem dessa diferença. Enxergada agora desde o que poderíamos chamar de duplo regime de invisibilidade, isto é, o do gesto que não se conforma com a cidade planejada e asséptica - e que com isso aproxima essa forma de intervenção da pichação ${ }^{8}$ - e aquele decorrente de uma prática híbrida e mestiça ainda dominada por homens, a escrita de mulheres na cidade pela via das tags responde a um procedimento em que o corpo ocupa estrategicamente $o$ espaço urbano desde um lugar de enunciação próprio e diverso que ultrapassa o papel de apoio, musa e/ou motivo, uma presença marginal e marginalizada em suma, que está inscrito nos primórdios do graffiti hip-hop de maneira semelhante àquele que as mulheres ocupam dentro da história da arte.

Precisamente, a questão do corpo é nodal no desenvolvimento do corpus de mulheres artistas tanto na arte global quanto na arte da América Latina de meados do século XX em diante. Para Andrea Giunta (2018, p. 29), no caso das artistas latino-americanas foi a partir de uma intensa reflexão crítica sobre os corpos e as sensibilidades das mulheres - fixadas até então à biologia, a tabus e a estereótipos ligados ao modernismo branco e heteronormativo - que suas produções artísticas redescobriram o corpo, e, com ele, uma "nova concepção de corpo que ativou um saber que desencadeou sensibilidades até então nunca expressas em imagens", inaugurando um projeto estético e político amplo que

8 Embora não desenvolvida neste texto, a pichação, uma linguagem eminentemente brasileira e periférica, pode se considerar enquanto uma forma de expressão "anárquica" que não pretende se comunicar com a cidade, mas questioná-la. Este "agente verticalizador das letras" (Pixo, 2010) supõe a existência não só de formas diferentes de execução às do graffiti, mas um forte componente destrutivo associado à adrenalina e ao risco. O significado da pichação, além da procura de reconhecimento social, de lazer e de uma descarga de adrenalina, está vinculado às reconfigurações da paisagem urbana, pois, nas palavras dos próprios pichadores, ela "acompanha a forma da cidade como se ela fosse um caderno de caligrafia". Cf. Pixo (2010). 
"não estava atrelado a uma pauta única e unificada, mas que era formulado em diferentes contextos, com base em estratégias culturais e históricas especificas". Essa perspectiva, que vai ao encontro do levantado por Costa (2002) no sentido de compreendermos a experiência das mulheres mais na micropolítica de sua vida cotidiana, nas suas lutas e nos seus processos de resistência às pressões dos enquadramentos históricos, do que desde posicionamentos essencialistas homogêneos (recuperando o "essencialismo estratégico" proposto por Gayatri Spivak), não somente oferece indícios sobre a necessária reconfiguração do campo da história da arte feminista, ${ }^{9}$ mas assume o corpo como campo de batalha na produção artística, como possibilidade de subversão dos sistemas de representação e como domínio de emergência de novos saberes:

Como lascas de corpos, sensibilidades e conceitos, essas obras nos dão a sensação de um saber diferente, de novas linguagens e afetos. Se não fosse pela redescoberta do corpo e pelo descomprimir do espartilho essencialista que atrelara a sexualidade à biologia, provavelmente teria sido impossível habilitar a variedade de sensibilidades e escolhas sexuais que habitam os corpos, mesmo numa sociedade na qual eles são divididos entre femininos e masculinos. (Giunta, 2018, p. 32).

Como poderia se pensar, então, a passagem da representação do corpo nas obras de arte para a exposição e o uso performático e em muitos casos anônimo do corpo por parte de mulheres em práticas artísticas ${ }^{10}$ como o graffiti, particularmente realizadas no espaço público, sem desconsiderar que mesmo com

9 De acordo com Giunta, para a constituição da história da arte feminista como um campo autônomo, existiria uma distinção fundamental a se traçar entre artistas feministas e feminismo artístico. Enquanto as artistas feministas são aquelas que deliberada e sistematicamente "tentaram construir um repertório e uma linguagem artística feminista”, o feminismo artístico é o posicionamento das/dos historiadores/as que estudam a arte baseados na pauta feminista.

10 Em termos da distinção entre práticas estéticas e práticas artísticas, assumem-se as primeiras, junto com Rancière (2009, p. 17), como "formas de visibilidade das práticas da arte, do lugar que ocupam, do que 'fazem' no que diz respeito ao comum", enquanto que as práticas artísticas se referem a "formas de fazer que intervêm na distribuição geral das maneiras de ser e formas de visibilidade". A partir disso, entende-se que os atos estéticos não somente remetem a experiências da sensibilidade vinculadas à arte, mas também, especialmente, a formas de visibilidade tanto das práticas estéticas quanto das práticas artísticas que articulam o que ele vai denominar "regime estético das artes", um regime que "identifica a arte no singular e desobriga essa arte de toda e qualquer regra específica, de toda hierarquia de temas, gêneros e artes [...]” (Rancière, 2009, p. 34). 
a reformulação de valores estéticos possibilitada por um grupo considerável de artistas ainda existe o preconceito que assume que as artistas mulheres não são tão boas quanto os homens artistas? Ainda que dita passagem tenha acompanhado os desdobramentos dos feminismos e suas distintas lutas, frentes e conquistas, processos de invisibilidade vinculados ao sexismo dentro da arte se mantiveram sobre as artistas tanto nos museus quanto no espaço público. ${ }^{11} \mathrm{E}$, mesmo que, como salienta Cecilia Fajardo-Hill (2018, p. 21), "o posicionamento contra a ordem estabelecida, o experimentalismo, a originalidade e o não conformismo" sejam qualidades celebradas nas práticas estéticas no século XXI expressas de forma contundente em práticas como o graffiti - uma enorme suspeita é levantada sobre o trabalho das mulheres artistas, pois a qualidade e a visibilidade de suas obras e intervenções são condicionadas ao sucesso.
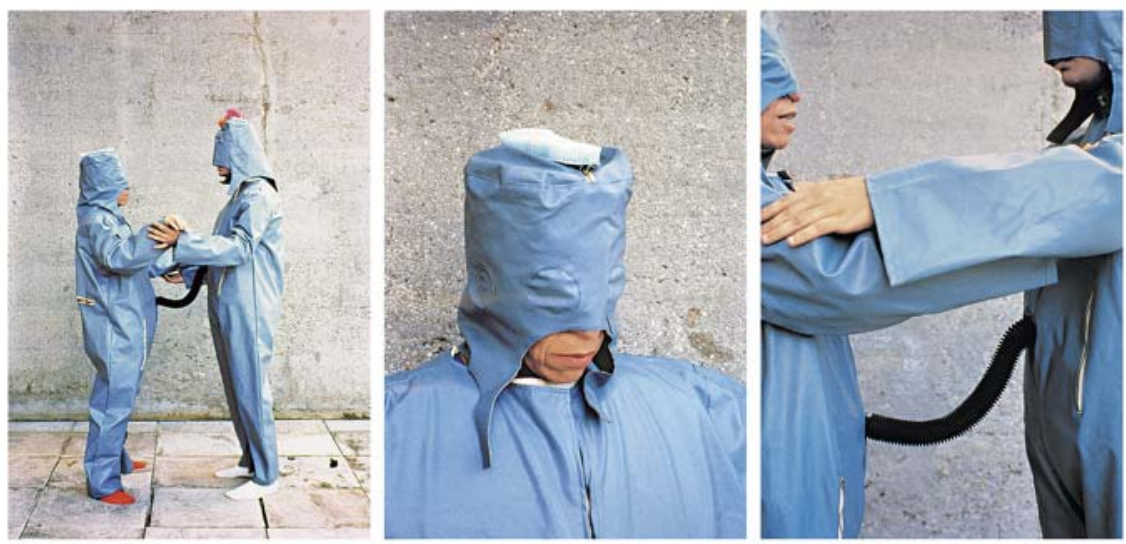

Figura 6. O eu e o tu: Roupa-corpo-roupa (1967), Lygia Clark (Hammer Museum, 2018).

11 A propósito da exibição das Guerrilha Girls (Pedrosa; Bechelany, 2017) organizada pelo Masp em 2017, fica em evidencia que ainda hoje existe, na arte latino-americana e internacional, uma presença limitada de mulheres tanto no âmbito de exposições quanto no de acervo dos museus. Segundo estatísticas do próprio Masp, "apenas $6 \%$ dos artistas do acervo em exposição são mulheres, mas $60 \%$ dos nus são femininos", um contraste que demonstra que ainda opera a invisibilidade das artistas dentro do regime estético, mas também o papel desempenhado pelas mulheres na arte e os constantes apelos ao corpo das mulheres como motivo da arte consagrada e executada por homens. 
Eis que o corpo e a presença dos corpos das mulheres retomam importância. Dado que as obras das mulheres esvaziam de conteúdo gradativamente o olhar artístico do Outro (que as concebe principalmente como modelos/objetos de desejo/símbolos de feminidade) a partir da ressignificação dos seus corpos e sensibilidades, o que está em jogo evidentemente não é a busca de sucesso na arte, mas a obrigação de visibilidade desde a tentativa constante da expansão da sensibilidade coletiva partindo de seus lugares e experiências de criação artística.

Produtoras, espectadoras e sujeitos do olhar (Pollock, 2013), é possível identificarmos, portanto, a presença pública das mulheres na cidade e especificamente na prática do graffiti do ponto de vista de uma autoria que, mesmo que seja anônima, é tecida e mantida nos modos distintos de criar e praticar a cidade e está ancorada de forma crítica tanto às assimetrias de poder persistentes no uso do espaço público entre sujeitos masculinos e femininos quanto em relação com os usos da linguagem e com a persistência da diferença sexual no campo da arte. Não se trata de assinalar as desvantagens operativas envolvidas nos processos de criação das mulheres escritoras de graffiti - que são muitas e remetem sobretudo ao caráter performático, muitas vezes clandestino e transgressor por trás do contrauso dos muros e outros suportes urbanos de escrita - mas de reconhecer que nessa diferença sexual existente nas formas de apropriação do espaço público é disputada uma visibilidade mais ampla que chama a atenção sobre a legitimidade da criação nos processos expressivos e suas possibilidades políticas e estéticas no contexto das cidades. Se dita disputa hoje se concretiza cada vez menos desde o anonimato isso não tem tanto a ver com o trânsito da prática da clandestinidade para sua aceitação progressiva, senão com o fato de que a voz das mulheres, seus corpos e experiências reconfiguram os modos de enunciar e de participar da experiência coletiva urbana ${ }^{12} \mathrm{e}$, com isso, formam parte da autoria da cidade contemporânea, de sua escrita e suas leituras.

Na América Latina são cada vez mais variadas e abundantes as aproximações acadêmicas sobre o gênero e o graffiti (Hernández, 2012; Nicolau, 2016;

12 Nesse sentido vale a pena mencionar as recentes e multitudinárias formas de apropriação do espaço público em função das demandas dos movimentos feministas pela descriminalização do aborto em alguns países da América Latina e em cidades estadunidenses e europeias. 
Pérez Santos, 2017). Os exemplos sobre a participação de mulheres na escrita das cidades são inúmeros. Cabe nesse sentido mencionar o graffiti que produz o coletivo boliviano feminista e anarquista Mujeres Creando organizado por María Galindo e Julieta Paredes; o trabalho multifacetado de Mag Magrela no Brasil e as intervenções de forte vínculo com o hip-hop da Mickey em Buenos Aires. Sem perdermos de vista os contextos dissímeis de apropriação das cidades nas quais desenvolvem sua prática, essas escritoras têm em comum o apelo a um trabalho autônomo e crítico do lugar comum em que são colocadas as artistas mulheres tanto no âmbito público quanto no privado, e atento às possibilidades estéticas e políticas da inscrição de suas perspectivas de mundo no espaço público.

Se as cidades, retomando a Calvino, sempre se tomaram como femininas e por isso enquanto objetos de desejo e de conquista, a escrita de graffiti por parte das mulheres, seu gesto, operaria uma reapropriação dessa perspectiva do feminino, dessa restrição prática, artística e política que, desde a diferença sexual e da linguagem, supõe um papel secundário ou estreitamente vinculado ao discurso sobre a feminilidade nas intervenções das grafiteiras. A potência da visibilidade das mulheres na cidade a partir da prática do graffiti mais ilegível, a tag, não só mostra estratégias de reconquista da cidade e sua paisagem, mas um reposicionamento estratégico sobre o imaginário urbano escrito com nome de mulher: as cidades contemporâneas também são feitas de seus gestos sem fim.

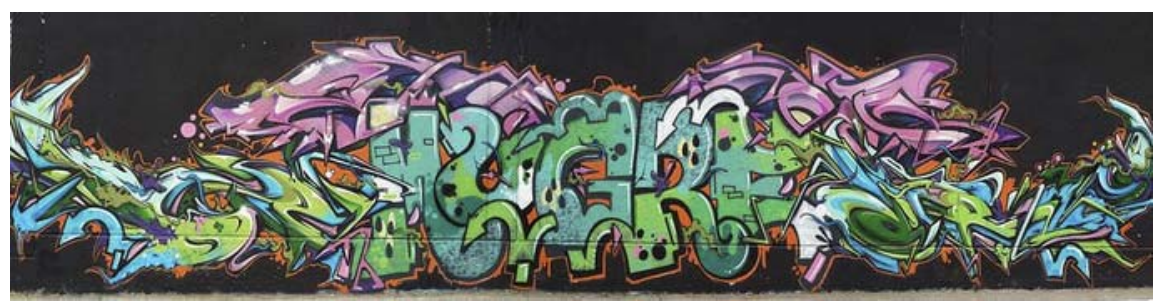

Figura 7. Mugre Diamante (2014). 


\section{Referências}

BARTHES, R. S/Z. Tradução Léa Novaes. Rio de Janeiro: Nova Fronteira, 1992.

BARTHES, R. Variaciones sobre la escritura. Barcelona: Paidós, 2002.

BRACAMONTES, E. Más desvelos necessários. Facebook, 15 abr. 2015. Disponível em: https://www.facebook.com/photo.php?fbid=10206848092660439\&set =pb.1220303597.-2207520000.1570144647. Acesso em: 30 out. 2018.

CALVINO, I. As cidades invisíveis. Tradução Diogo Mainardi. São Paulo: Companhia das Letras, 1990.

CAMPOS, R. Porque pintamos a cidade?: uma abordagem etnográfica do graffiti urbano. Lisboa: Fim de Século, 2010.

CANEVACCI, M. A cidade polifônica: ensaio sobre a antropologia da comunicação urbana. 2. ed. São Paulo: Studio Nobel, 2004.

COSTA, C. O sujeito no feminismo: revisitando os debates. Cadernos Pagu, Campinas, n. 19, p. 59-90, 2002.

DE MARTINELLI, L. Plagar: el graffiti desde el Bronx a La Plata. La Plata: Malisia, 2017.

DIDI-HUBERMAN, G. (org.) Levantes. Tradução Jorge Bastos; Edgard de Assis Carvalho; Mariza P. Bosco; Eric R. R. Heneault. São Paulo: Edições Sesc, 2017.

FAJARDO-HILL, C. A invisibilidade das artistas latino-americanas: problematizando práticas da história da arte e da curadoria. In: MULHERES radicais: arte latino-americana, 1960-1985. Curadoria e textos: Cecilia Fajardo-Hill, Andrea Giunta. São Paulo: Pinacoteca de São Paulo, 2018. p. 21-27.

GACHE, B. Consideraciones sobre la escritura asémica: el caso de Mirtha Dermisache. In: MIRTHA Dermisache: porque iyo escribo!. Buenos Aires: Fundación Espigas-MALBA, 2017. p. 15-31.

GÁNDARA, L. Graffiti. Buenos Aires: Eudeba, 2015.

GARÍ, J. La conversación mural: ensayo para una lectura del graffiti. Madrid: Fundesco, 1995.

GIUNTA, A. A virada iconográfica: a desnormalização dos corpos e sensibilidades na obra de artistas latino-americanas. In: MULHERES radicais: arte latino-americana, 1960-1985. Curadoria e textos: Cecilia Fajardo-Hill, Andrea Giunta. São Paulo: Pinacoteca de São Paulo, 2018. p. 29-34. 
GÓMEZ DAZA, A.; ESTER, B. Blancas, prolijas y seguras: ciudades derechas. 2017. Disponível em: http://www.celag.org/blancas-prolijas-y-seguras-ciudades-derechas/. Acesso em: 22 out. 2018.

GRAVANO, A. Palimpsesto urbano: sobre-escritura de huellas diacrónicas de la ciudad imaginada. Etnía, n. 42-43, p. 47-67, 1999.

HAMMER MUSEUM. O eu e o tu: Roupa-corpo-roupa (The I and the you: Cloth-bodycloth). Radical Women: Latin American Art, 1960-1985. Digital Archive. Los Angeles, 2018. Disponível em: https://hammer.ucla.edu/radical-women/art/art/o-eu-e-o-turoupa-corpo-roupa-the-i-and-the-you-cloth-body-cloth/. Acesso em: 30 out. 2018.

HERNÁNDEZ, L. Aproximaciones al análisis sobre graffiti y género en México. Revista de Estudios Urbanos y Ciencias Sociales, México, v. 2, n. 2, p. 133-141, 2012.

KOZAK, C. Contra la pared: sobre graffitis, pintadas y otras intervenciones urbanas. Buenos Aires: Libros del Rojas, 2004.

MICKEY. \#CromoyNegro. Facebook, 31 mar. 2014. Disponível em: https://www.facebook.com/MickeyGraffiti/photos/a.211961702208089/628199940584261/?type=3\&th eater. Acesso em: 30 out. 2018.

MUGRE DIAMANTE. Básica entre salvajes en el Callao: ft. Dear - Hado. Facebook, 2 abr. 2014. Disponível em: https://www.facebook.com/mugrediamante/photo s/a.545095238923059/573609299404986/. Acesso em: 30 out. 2018.

MUGRE DIAMANTE. Los luces. Facebook, 17 ago. 2017. Disponível em: https://www. facebook.com/mugrediamante/photos/a.1398804780218763/1398804760218765/. Acesso em: 30 out. 2018.

MUJERES Creando grafitea y echa pintura a fachada de Katanas. Agencia de Noticias Fides, 30 set. 2016. Disponível em: https://www.noticiasfides.com/ nacional/sociedad/mujeres-creando-grafitea-y-echa-pintura-a-fachada-de-katanas--371013-370906. Acesso em: 30 out. 2018.

MUMFORD, L. A cidade na história: suas origens, transformações e perspectivas. Tradução Neil R. da Silva. São Paulo: Martins Fontes, 1998.

NICOLAU, C. “Minas de minas": trajetórias de mulheres grafiteiras na cidade de Belo Horizonte. In: ENCONTRO NACIONAL DA ANPOCS, 40., 2016, Caxambu. Anais... Caxambu: Anpocs, 2016. p. 1-30.

PEDROSA, A.; BECHELANY, C. Guerrilha Girls: gráfica 1985-2017. São Paulo: MASP, 2017. PÉREZ SANTOS, T. Arte urbano, graffiti y activismo feminista: un recurso para la educación social. 2017. Trabajo fin de grado (Grado em Educación Social) - Facultad de Educación de Palencia, Universidad de Valladolid, Valladolid, 2017. 
PIXO. Direção: João Wainer; Roberto T. Oliveira. Produção executiva: Roberto T. Oliveira. São Paulo: Sindicato Paralelo de Filmes, 2010. 62min. Disponível em: https:// www.youtube.com/watch?v=skGyFowTzew. Acesso em: 23 out. 2018.

POLLOCK, G. Visión y diferencia: feminismo, feminidad e historias del arte. Tradução Azucena Galettini. Buenos Aires: Fiordo, 2013.

RAMA, A. La ciudad letrada. Montevideo: Arca, 1998.

RAMOS, L. Las ciudades de letras de Ítalo Calvino. Bodegón con Teclado, 28 jan. 2012. Disponível em: https://bodegonconteclado.wordpress.com/2012/01/28/las-ciudades-de-letras-de-italo-calvino/. Acesso em: 22 out. 2018.

RANCIÈRE, J. A partilha do sensível: estética e política. São Paulo: Editora 34, 2009.

SARLO, B. Notas sobre ciudad y memoria. Buenos Aires: Biblioteca Nacional, 2015.

SILVA, A. Graffiti: una ciudad imaginada. Bogotá: Tercer Mundo Editores, 1988.

SIMON, E. Expo photographie contemporaine: “SOULÈVEMENTS”. Actuart, 25 out. 2016. Disponível em: http://www.actuart.org/2016/10/expo-photographie-contemporaine-soulevements.html. Acesso em: 30 out. 2018.

Recebido: 31/10/2018 Aceito: 15/04/2019 | Received: 10/31/2018 Accepted: 4/15/2019 